Article

\title{
Violence as an Environmentally Warranted Norm amongst Working-Class Teenage Boys in Glasgow
}

\author{
Christopher Holligan and Robert McLean * \\ Interdisciplinary Research Unit on Crime, Policing and Social Justice, School of Education, University West of \\ Scotland, Ayr KA8 OSX, UK; chris.holligan@uws.ac.uk \\ * Correspondence: robert.mclean@uws.ac.uk; Tel.: +44-014-1848-3000
}

Received: 16 August 2018; Accepted: 18 October 2018; Published: 22 October 2018

\begin{abstract}
This study aimed to contribute to knowledge about contexts of violent assault perpetrated by white working-class teenage boys in Scotland. Despite studies exploring Scotland's adolescent street gangs, there remains a gap in research where the collateral damage caused by gangs to others of the same class, age, and gender has gone unrecognized. Drawing upon insights from qualitative interviews with young, male, former offenders in Scotland we found that violence contained a strategic logic designed to foster bonding to a delinquent group, whilst offering a celebrity status and manliness. The co-presence of a violent culture worsened the likelihood of ameliorating mentalities associated with anti-social behaviors, which appear endemic to masculinity. That context of violence is associated with the criminal offending of boys who, though they may not be gang members, were nevertheless 'contaminated' by the aggressive shadow cast by the protest masculinity of gang-conflicted territories in disadvantaged neighborhoods.
\end{abstract}

Keywords: gangs; violence; Scotland; sub-culture; Glasgow

'If some cunt tried tae attack me ... I'd severely fuck the faggot up and he'd no be

trying it again.'-(Derek)

'I stayed in (Glasgow area) and knew everybody, but this place is junkies,

immigrants, and that sort of people. I always keep a chib (Weapon) [in case

confronted by a would-be assailant].'-(Bob)

\section{Context}

The functionality of violence can be glimpsed in the quotations above; it serves a retaliatory role and is required for personal protection. Whilst these functions are examples of its warrant, the verbal idiom crafts a deeper narrative concerning hegemonic masculinity. Adolescence is not necessarily a period of storm and stress: there may be a smooth transition from childhood into adulthood depending upon the culture through which this 'rite of passage' articulates (Deuchar 2009). However, for the working-class teenage Glaswegian boys who participated in the current study it is a process of 'edge work' required for survival in potentially emasculating material and political conditions. If Bauman (2004) is correct in arguing that we inhabit a 'liquid modernity' characterized by the demise of tradition, rapid pace of social change, and instability, then we would expect the 'rite of passage' for adolescents in excluded areas to be tortuous. Neither 'Bob' nor 'Derek' seem to know those around them, and so personify the anomie associated with 'liquid modernity' and resonate with Walker (2006) emphasis on an anomic form of 'protest masculinity'. Our study's focus upon the societal perceptions of marginalized youth offers a micro-sociological examination of Bauman's thesis. Our research question asks: What resources do teenage boys draw upon to construct social realities 
in chronically poor criminogenic neighborhoods? How does their 'protest masculinity' connect with a sense of place? In liquid modernity, welfare provision, so important to the well-being of those marginalized by globalization, is a financial burden on the community, and the excluded are re-cast as lazy and indulgent (Best 2016). Laslett describes how status in the pre-industrial world accompanied occupation. In the post-industrial landscape, the material condition behind the lives of this study's participants: that status opportunity is often missing from the places they encounter.

Peer pressure to conform is especially significant in affecting behavior and attitudes during adolescence. The presence of others, including their support or otherwise, such as anti-social peer affiliation, strongly impacts behavior (Quin et al. 2018). Adversity and tension are negatively experienced and often problematic aspects of life, wherein sometimes they result in outcomes which are beneficial to society and individuals, but sometimes they change lives for the worse by promoting a criminogenic coping strategy. Poverty and violence are associated throughout the world, creating conditions where anxiety and stress are indictors of the liquid modern. Glasgow, like other Scottish cities, includes socially deprived housing estates characterized by the enduring presence of street gangs (Bartie 2010; Bradshaw 2005; Davies 2013). Glasgow is arguably an 'ideal-type' for studies of adversity in terms of its intractable subculture of violence and celebrity criminals. Statistics for knife crime, rather than gun crime, are evidence of its distinctiveness; hands, feet, and head, and opportunistic weapons such as bottles are notable assault tools, often used to catastrophic effect (Davies 2013; Deuchar and Holligan 2010; Holligan and Deuchar 2014; Deuchar et al. 2014; Patrick 1973). Glasgow has more street gangs composed of mainly white teenage boys than anywhere else in the UK. The following graph below (Figure 1) offers official data and depicts Glasgow's significantly higher crime statistics in a Scottish context. ${ }^{1}$



Figure 1. Violent crime and offences in Scottish Cities 2016/17.

Tension impacts upon agency and informs cognitive scripts. The nature of the social ecology in which young people live cannot be understood in isolation from the norms of a wider society (Ellis et al. 1978). While interpreting group dynamics in the article, external factors, the urban environment, provide a necessary tension for group unification, and must therefore be acknowledged. (Ellis et al. 1978). Tension may 'achieve' a confrontational effect by injecting fear and anxiety into the social fabric of areas' and yet without tensions groups struggle to exist (Klein 1971). In this way, tension is a social balm giving the cement that adds duration to a group such as a youth gang, or less identifiable adolescent peer groupings. Similarly, Glasgow's violent street gangs cannot be examined 
without investigating subcultural settings which precondition gang emergence, and, as a corollary, cast a negative shadow upon teenagers living within territories claimed by gangs.

Tension, as a productive psychological capital, arguably gives rise to social formations whose identities are inflected by entrenched environmental adversity. Violence is undoubtedly productive of tension, but paradoxically violence can mobilize social cohesion, such as when delinquent youths develop their sense of togetherness and belonging through acts of violence towards property or persons. By assaulting those outside their group, the identity of the group is strengthened in tandem with processes of othering. A shared history of collective enterprise fosters interpersonal ties and violence capital. Adolescence is classically a volatile period associated with 'storm and stress', according to Stanley Hall's (1842-1924) psychological account. If turmoil lies at the core of adolescence, then it is to be expected that individual adaptation to threat or tension may entail recourse to a protective aggressive impulse.

Violence is understandably common in the academic portrayal of Glasgow (Davies 2013). Gray (1989) argues the city's reputation for volatility and aggression can be traced back to late Victorian period, where mortality rates among infants were high, criminal justice tariffs retributively biased, diseases severely reduced life chances, and the law permitted men to use violence to exercise control over their wives and children. Moving into the twentieth century, Glasgow would controversially be coined 'The Scottish Chicago' as having disproportionately high levels of criminal violence proliferated (Davies 2013). Urbanization and industrialization throughout late 19th and early 20th century saw an inwards migration of highlanders, rural countrymen, and Irish settlers (Holligan and Deuchar 2014). Such an accelerated expansion in population and immense pressure on housing arguably weakened protective kinship networks, a loss that engenders vulnerability. The violence typifying 'protest masculinity' is prevalent in post-industrial areas, where intergenerational unemployment, particularly amongst the adult male workforce, is the norm. Violence can become a form of capital connected with reputation and self-esteem, which is known to exist in the vectors of urban landscapes with fragile social capital and the anxieties associated with feelings of insecurity (Davies 2013; Holligan and Deuchar 2014; King 2011). Protest masculinity, whilst originating in marginalizing political and material conditions, refers to the adoption of a type of aggressive agency to challenge a sense of injustice. As its name implies, protest masculinity is gendered and typifies a class status where aggression is not taboo.

Aggressive male identities are prevalent, especially within working-class heterosexual male socialization in Glasgow, a city that still valorizes its footballing culture (Whitehead 2002). Mainstream society's cultural acceptance of a hegemonic value system (Connell 2005) incorporating aggressive elements, contributes to the emergence of subcultures that exist in parallel to mainstream norms among some socially excluded populations (Holligan and Deuchar 2014). Such distortions of the widely accepted social norms, which rely upon the law to address and resolve disputes, adapt and exploit in ingenuous ways pre-existing value systems to promote an anti-social masculine identity: Kupers (2005) calls it 'toxic masculinity'. This kind of toxic identity is often also misogynistic, rejecting anything perceived to be feminine, and together with the passivity and decorative style that accompany this myth of the feminine, which includes certain colors, physical and mental postures, leisure interests, and speech styles. Instead, the agency of the toxic masculine identity thrives on seeking confrontation rather than de-escalation and compromise; the latter are attributes of a contested notion of femininity (Mullins 2006). For working-class adolescents, 'doing crime' or simply being anti-social is a requirement of 'doing masculinity' (Messerschmidt 1993). In this sense their masculinity is a performance, and we suggest, compensates for the demise of manly occupational opportunities. To understand this notion of masculine performance and its underpinning in violence capital it is necessary to examine the 'stage' on which it presents itself, wherein it nurtures oppositional dispositions. In the next section of the literature review, we analyze sources and drivers of a resilient 'protest masculinity'. 


\section{Emergent Subcultural Violence}

Mainstream culture unwittingly accepts an aggressive adolescent subculture. Such a valorization of a 'protest masculine' performance is explicable in terms of blocked opportunities for social and employment mobilities; where there are restrictions on access to legitimate outlets for the expression of a traditional working-class masculine identity. That type of hegemonic identity depends upon the abundance and circulation of physical capital (Johnston and McIvor 2004). Previously, heavy industry in the Glasgow played a pivotal role in the development and maintenance of the British Empire (Devine 1999). In eighteenth century Scotland, patriotic masculinities characterized the gentleman soldier whose martial manhood was characterized by courage, loyalty, and sacrifice (Carr 2008), a type of masculinity exported from the Highlands of Scotland throughout the British Empire. Opportunities to engage with risk and dangerous situations overseas offered social mobility to working-class men, and rewarding sources for their propensity for masculine identification and the esteem it conferred.

Following the demise of colonialism and the shift overseas to Asia and the Far East of many Scottish industries later in the twentieth century, coupled with the hostility experienced through neo-liberalism's privileging of the commercial market over collective welfare, subcultural violence become an outlet for a new generation seeking to achieve a traditionalist heterosexual masculine identity suited to patriarchy (Deuchar 2009; Holligan and Deuchar 2014; Johnston and McIvor 2004). The esteem associated with violent contact sports such as boxing (Cooley 2010; Wacquant 2004; Woodward 2014) in areas of deprivation is symbolic of the continuation of the Glaswegian 'hard man' social norms. The latter was forged through heavy industry labor, certain forms of sport, and a canon of criminal biographical literature by notoriously violent Glaswegian men, such as Jimmy Boyle (Boyle 1984; Fraser 2015; Jeffrey 2002).

Throughout industrialization manly identities were forged in collective all male labor-forces undertaking physically dangerous and demanding tasks, long days, and night-shifts down the coal mines or in the shipbuilding industry. Johnston and McIvor (2004) identified the association of dangerous work, hard men, and masculinity in the heavy industries of Glasgow's Clydeside from the 1930s to the 1970s. Even the morning walk to work provided opportunity for togetherness and supportive male banter. Social and family capital was produced through these climates of togetherness and male bonding to collective endeavor. The construction industry remains one of the most gender segregated labor forces, where male construction workers' masculine identity is defined in relation to the conditions of this tough job; Ness (2012) argues that the industry sustains existing power relations; Lacuone (2005) found real men are perceived to be tough guys in the construction industry. Opportunities in the increasingly liquid structure of the 21st century rely upon the very different service economy, where performance is individualized and subject to intense human resource management oversight. Service economies expect subservience and deference towards customers, qualities that many might classify as feminine virtues. Youths within marginalized populations in isolated communities on the outskirts of the city pursue recreational opportunities to satisfy an inter-generationally transmitted class identity of manliness. Peripheral housing estates lack bonding mechanisms that attach individuals to the norms of mainstream society, and the isolation of these geographic liminal zones has been further exacerbated by the re-drawing of urban boundaries (Mullen et al. 2007).

Correlations between delinquency and socially disadvantaged communities are well established (Deuchar 2009; Deuchar 2013; Holligan and Deuchar 2014; Gray 1989; King 2011; Mullen et al. 2007; Rodger 2008; Sutherland 1947; Thrasher 1927), and yet, comparatively little is known about whether or not community tensions, and tensions connected with exclusion, play a role in how violence is perceived and utilized by working-class lads, including those who are believed to be gang-associated. Sutherland (1947) suggests a key indicator for increased risk of delinquent participation to be disproportionate delinquent association, and this view is supported by drift theory. Underestimation of the efficacy of social influence can lead us to overlook the importance of social bonds, both to 
wellbeing and to perceptions of normal behavior, i.e., exposure to delinquency relaxes notions of law-breaking as unacceptable behavior and legitimizes an oppositional mentality (Smith 2006).

The texture of micro-social interactions is colored by an individual's construction of social externalities impacting their routine activities and perception of place. We posit that, non-delinquent teenage lads in socially disadvantaged neighborhoods are more likely to associate with delinquent peers, who are also possibly local celebrities due to their possession of violent street capital. In this way, these youths often become co-offenders through a process of intermittent criminogenic cultural drift (Matza 1964; Falco Metcalfe and Baker 2014). Adolescent members of deviant sub-cultures or those with a machismo attitude are more likely to engage in violence (Austin 1980). The need for recognition for peer status intensifies during adolescent transition, whilst pro-social role models are often discarded temporarily as too tame and inappropriate (Sutherland 1947). Individuals surrounded by delinquency, given certain neighborhood characteristics in primary (family), secondary (schools) institutions, and 'the street', are even more at risk of displaying a delinquent habitus (Coster and Heimer 2001). Pathways for deviancy are also influenced by structural positions in a class hierarchy (Link and Phelan 1995), and are projected onto other places and persons that are believed to be similar, and thus companionable.

The communities characterized in this article have shared histories and sociology, which enable localized aspects of offending occurring within just one community to be projected as generalizations that are valid regarding the social texture of different communities (Innes and Fielding 2002). Thus, subcultures existing in one community can quickly become projected and believed to be identifiable in other neighborhoods (Rodger 2008). Historically, Glasgow has housed a predominantly Scottish and Irish immigrant population, and during the early twentieth century had some of the worst overcrowding in Britain. Crime historians of Glasgow (Davies 2013) have documented sectarian gangs and razor gangs. It is unsurprising that a volatile subculture simmers underneath these historical processes as generations now encounter an unappealing post-industrial space, where gaining secure and rewarding employment is a remote prospect. We suggest that this disabling cultural heritage impacts youth agency and their social construction of reality. Our over-arching argument is that tension and violence inter-link with the biographies lying within local cultural history. We also submit that, urban 'regeneration' and re-modelled urban geographies of neo-liberalism are likely to intensify the predicament of our participants.

\section{Methodology and Participants}

Qualitative data was gathered during 2013-2016 by the authors. The sample forming the basis of this article consisted of thirty-four males, whose ages ranged from mid-adolescence to their twenties, from working-class backgrounds as defined by parental occupation, status, and income. They were domiciled in former council housing estates, whose stock was transferred to the private sector. This urban conurbation belongs to Scotland's most socially deprived areas within the larger Glasgow conurbation. Participants, to merit selection, had to have experience of being involved with a gang and/or street violence, or other forms of offending and be over 16 years of age. Gatekeepers were used for initial access to a sample. Christian-operated organizations based in the areas where the sample lived helped in the identification of offenders for the study. Once participants had been accessed, a snowball sampling method was applied thus widening the scope of the research sample background. Our interview schedule was semi-structured to create consistency and to give scope to the expression of difference. In designing it, we aimed at the following: To explore subcultural values among young males and adolescents in Glasgow, giving them the opportunity to control the research process, and to foreground their own narratives about their lives, as males, living in disadvantaged areas. An inductive approach to data analysis and the identification of three interconnected themes described below was adopted (Flick 2014; Silverman 2011). Pseudonyms are used throughout. 


\section{Thematic fields Hegemonic Masculinity as Entrapment}

The social bonding mechanisms required for full integration into mainstream culture is restricted, Deano explains:

'Nae cunt employs guys fae my bit in good jobs. I want tae work in a decent job but when you're up against people fae like Giffnock, The Mearns, and that, then who they [The employer] going to pick?'-(Deano)

'I attended school...but let's be honest mate when you're at school you think it's only gays that study (Laughs).'-(Tom)

Deano crafts exclusion from employment as based upon the relative prestige of area post codes, and Tom argues that commitment to school symbolizes femininity, coded as "only gays." This perception supports an established body of literature identifying ties between class and hegemonic masculinity (Connell 2005) combining aggression (Whitehead 2002). Schooling is perceived as hopeless in terms of providing access to the labor market. With shaky logic, Michael justifies his hostile rejection of school on the basis that it made no difference to him finding a job:

'I thought school was a pure waste of time mate ... I didn't like it that much. Dogged it quite a bit, when I could. [Big sister A] would leave to go to work about quarter past 8 or round about then ... I had to leave at same time so my mum knew I wasn't dogging it in house ... [but] I would take the patio keys from the patio ... and sneak back in after [sister A] got the bus ... [friends B and C] always skipped reggie [registration] and would come to mine ... suppose we never seen the point in school ... It hasn't made a difference to me getting a job mate.'-(Michael)

His "dogging it quite a bit" suggests the experience may have clashed with his identity as a hegemonically oriented young working-class man. In the sociology of education, school tends to be classified through a feminine lens. Heterosexual masculinity within this class nexus of Glasgow is accompanied by a concept of women as status symbols to mark a man's success. One participant, Grant, for instance, argued that he needed to work in order to gain access to female partners: 'Need to work ... no burd's (female) gonna want a bum' (unemployed with no money). The vernacular is also prevalent in the expression of value and a tacit capitalist orientation, indicating that whilst exclusion affects many, the material aspirations continue to be mainstream capitalist goods and enjoyments (Davies 2013; Deuchar 2009). Grant articulates the Presbyterian wisdom of an earlier generation, shared significantly by his grandfather:

'Ma Granddad use to always tell me Glasgow boys are hard as nails ... "stop greeting ' $n$ ' bitching".

My family expect their boys [to be] like that'.-(Grant)

The phrase "hard as nails" conveys the aspirational resilient hegemonic masculine self which families "expect their boys" to fit. Earlier in the article, reference was made to male cultures of work and allegiance: Grant's grandfather communicates a similar memorable wisdom. Through the labor process, as presented in this paper, males earn their manly status, which includes material possessions and the capacity to protect their own family. His construction of masculinity was utilized not only to inspire Grant, but also to suggest an appropriate role model for young men:

'Ma old man would be on ma back telling me all the time, all yer family's grafters so you've the grafting gene in yae ... he was right enough...how can ye call yourself a man, if you've no job, no money, car, or canny even defend yer family.'-(Grant)

Our sample of participants expended vast amounts of effort and energy on obtaining those identifiable features and material goods perceivable by older male mentors as symbolic of the possession of masculine traits (Connell 2005). This ambition led some to the gym, taking regular exercise to build large muscles, playing sports in an aggressive manner, whilst working extra hours 
to obtain branded clothing, jewelry, and other material goods. These young men attributed much importance to accessing and ultimately cementing these capitalistic treasures that signaled material success in terms of its symbolic resonance for the projection of a hegemonic masculine identity (Connell 2005; Deuchar 2009). Musculature and competitive contact sports communicate hegemonic status to peers:

'I probably hit the gym about four, five times a week. Plus, I've been boxing twice. Football on Saturdays as well if ah'm picked.'-(Don)

The pursuit of masculinity generally coincided with the expectation that the more masculinity gained, the more easily socially ascribed goals would be achieved. Their social construction of reality is highly conventional rather than deviant or toxic, yet it is precisely the holding of these mainstream ambitions which appear to impact their anger. A man's social status and thus peer recognition from other males are interpreted in terms of these markers of accomplishment:

'Of course, ah'm better than him (speaking of a perceived rival), ah'm the one way the GTI (reference to a car type) and front door house ... what's he got? Some shitty dug and a skank burd (undesirable female partner)!'-(Stan)

The car type, housing type, the breed of dog, and attractiveness of female partner are the criteria used to measure worth and achievement. For this participant, coming out well from life-style comparisons requires both the possession of these desirables, but also the denigration of those without them. However, when these sources are unavailable or restricted due to poverty, the strain influences social norms favorable to illegal activities to bolster a faltering hegemonic male status. Lenny argues his recourse to criminal drug dealing was forced upon him by restrictions of age, criminal record, and education. His ambition is to belong by fitting into a comfortable life. His entrapment is two-fold: On the one hand, his past excludes him from the mainstream, but on the other hand, he can achieve conventional markers of success by recourse to a criminal career:

'Ah had no other option really when you think about it mate... I I sell drugs but ah'm no happy way it, course ah'm no. Would prefer to be legit ... My criminal record holds be back man ... All I want is to live a comfortable ... you know what ah'm saying.' - (Lenny)

'I didn't have an education and couldn't get a job. My [criminal] record was bad. I had no choice but to sell [illegal commodities]. [I] only want what everyone else has! Be [financially secure] and provide for [my children].'-(Ward)

Pessimism and determinism are characteristics of Ward's discourse about the reasons, educational and criminal, for his unenviable predicament. His construction of "no choice" implies he had no option but to become a criminal. His analysis shares biographical claims also presented by other voices within this theme. It would appear each is entrapped by a folklore narrative which 'speaks' through them, and helps justify their construction of exclusion and criminality. Michel Foucault is renowned for his determinism about the human condition, arguing that discourses 'speak' through us and control us accordingly. Many young people sampled considered themselves living on the peripheries of society with structural impacts, such as educational failure or a criminal record, controlling their agency and opportunity. That pattern of analysis within this theme references cultural causes, not individual psychology, and echoes beyond contemporary Glasgow (Deuchar 2009, 2013; Deuchar et al. 2014; Patrick 1973). Their aspiration for hegemonic masculine status is a factor implicit in the unhappy circumstance they report.

\section{Boys' Constructions as 'Protest Masculinity'}

This study identified an aggressive undercurrent throughout the literature and sample narratives, justifying attributing a hegemonic masculine identity to areas of Glasgow (Whitehead 2002). Walker (2006, p. 5) describes 'protest masculinity' as "a gendered identity oriented toward a protest 
of the relations of production and the ideal type of hegemonic masculinity." When confronted by stigmatizing work and economic marginality, working-class men emphasize their masculinity. In our participants' words, we can recognize what Walker calls 'anomic protest masculinity'. Our terminological use of 'toxic' is intended to convey the disruptive dimension of the protest masculine form. There is proliferating "face-work" and sense of self-and-other destructiveness in the protest enterprise (Walker 2006, p. 7).

Connell (1995) considered that protest masculinity involves claims to power without the resources to support them. This subcultural value system is in opposition to that considered feminine; demonstrated through narcissistic masculine displays of denigrating linguistics (typically considered homophobic or sexist), body language, beliefs, and behavior. Kupers (2005) refers to the rejection of all things perceived as feminine by the incorporation of overtly and often violent masculinity as toxic. Participants openly spoke about being extremely volatile if confronted by would-be-opponents attempting to assault them or insult their manhood:

Having a [penis] does not make you a man. Might make you look like one, but you earn manhood, know what ah'm saying mate. Guys are meant to be tough, y'know, you don't act like a woman, irrational and shit. [In]stead you think things through, do what needs to be done. You protect your family ... . when in school I would get into fights thinking it made me the big man, know aye. And it probably did in my mate's eyes, but there's always somebody out there harder than you ... . don't learn that till it's too late. Acting that way, being a man [through gang violence] seen me end up missing 6 months of my life [by being imprisoned]. I know now you can be a man, tough and shit, without having to get into trouble, [but] you don't think of that when you're young.-(Lenny)

Lenny has learnt the limitations of a protest masculinity. He experienced time in prison then grew out of a view of guydom as necessarily violent. Now his construction of manliness is without "getting into trouble", which means not fighting. Despite older participants being less likely to display toxic attitudes and partake in violent behavior, they nonetheless considered toxic behavior an acceptable social practice for adolescents and young adults. This was justified by favorably reminiscing about their own behavior during adolescence. Protest masculinity was accepted as typical male behavior by both older and younger generations:

'Of course [young males in Glasgow] get into trouble. What boy doesn't, growing up? Boys fight. That's what they do ... Boys will be boys .... if my [own son] wasn't getting into trouble I'd probably be worried to tell the truth.'-(Shrug)

Shrug tacitly endorses that his son is not an embarrassment on condition that he gets into trouble. The saying 'boys will be boys' frequently arose in interviews as males justified their own and their children's recourse to violence. Protest masculinity has a toxic component which legitimates violence (King 2011; Whitehead 2002). Delinquency and fighting are seen as attributes of the biology of male development, which enables male youths to participate in the inevitability of volatile behavior (Messerschmidt 1993). Mitch argues:

'I hung about way a lot of boys in school. It was a good laugh, but too many thought they [had more status] ... and get cheeky ... they would say "you scared, poof?" ... Got me into a lot of fights because I had to prove myself. We don't all hang about now. I say [hello] if I see them but couldn't hang about with them. They're alright in small doses.'-(Mitch)

Homophobia is associated in Mitch's biography with the protest masculine male, which assumes that a homosexual is necessarily cowardly. Peer hierarchic status was based upon the possession of fighting capital. Toxic masculinity is significantly heightened when youths 'hang out' with peers (Adelson 1980). Typically, it is expressed through playful camaraderie and apparently idle banter, but this morphs into volatile interchanges (Messerschmidt 1993). Labelling themselves and fighting with other groups of youths is a way to demonstrate gang affiliated status (Klein 1971). It is around 
this peer group from their 'scheme' (housing area) that they find a sense of belonging, particularly when gathering together to create larger structures for fighting those deemed outgroups (Matza and Sykes 1961). Geoff explains territorial conflict as follows:

'I stayed in [scheme A]. Was quite a big place I know, [because] it was like the whole town. No like [scheme B] down the road in [town C] ... that had like three [young street gangs] in [the one scheme]. We only had us, so we always outnumbered them. They were full of [bravado however], always scrapped, much as I hate them. Credit where its due. [There were] more of us than them .... [this included] about [list of censored names], and [list of censored names]. Probably around 35 boys aye, we could pull together about that ... when going to gang fight ... no joke. Most of the boys weren't fighters really mate. [Gang member A] always said but 'no[body] runs'. If [anyone did then] they would have to answer to [YSG member A]. So you'd prefer no to run.-(Geoff)

Fighting in packs is a rite of passage within the scheme world of perpetual rivalry and gang fighting. Geoff's place of domicile was his social world—it was a "whole town", suggesting he may have lived mostly within the scheme boundaries. Some boys may have been disinclined to fight, but the collective was ready to punish their 'femininity' if they ran away. Protest masculinity involves bullying others.

\section{Celebrity Masculinity: Benefits and Costs}

In this section, we explore the nature of celebrity status within the world of Glasgow's marginalized young men. Celebrity culture is associated with the commodification of everyday life, where new media forms have made celebrity status a potentially achievable goal (Stearns 2010). Celebrity provides a source of validation. Citing Max Weber, Furedi (2010) argues that the celebration of charismatic individuals is a response to the demise of tradition and the need for role models as a point of reference. Its impact was apparent in the lives of several participants: Robert's status, for example, is stigmatized because he lives in 'Feegie', an infamously deprived area. The self-fulfilling prophecy of labelling means Robert attempts to conceal his home area by revealing only his street name. Ross, in the second extract below, confronts celebrity status: His fighting capacity is an attraction he shares with Henry.

'Because am from [area a], well basically [area a] mate, other boys in my school would, you know, like think I am pure automatically going to be like this. A troublemaker, know what I mean. People do tar people being from there... [Secondary school] teachers [also] treated [people from area a] like we weren't as good as the other boys in the school. Cause they came from [more prosperous area] ... I don't think they meant it. It is just the stereotypes people have about [us] ... I don't say am from [area a] if ah'm out. I say ah'm from [street name] know, cause I do stay there. It is outside [area a] really, but people think it's all the same.'-(Robert)

'I go to parties or that sometimes, somebody might be like "av heard of you cause some fight you were in or your name" (As in reputation gained for fighting), depends man.'-(Ross)

'Folk didn't always [like] me when I was young. I know that, can be a bit hard to accept (laughs), but most probably talked away and hung out with me because I could fight ... . usually I could make folk do what I wanted.'-(Henry)

The violence capital they hold benefits them through its affordance of control over others. This celebrity masculinity has on the other hand, the cost of the pressure to maintain that reputation, which could easily be challenged. Social status in street gangs is determined by the ability to deliver violence. Individuals perceived by their peers to be able to deliver the greatest amount of violence, either through the self or extended networks, acquired high social status among the group. Arguably this could be attributed to the existence of an established or more pervasive hegemonic value system within mainstream society valuing risk, danger, and excitement. 
Group dynamics, it is clear, centered on toxic masculinity and the acquisition of violence as a source of capital, and therefore power (Bourdieu 1984). Consequently, this contributed to status being based upon the ability to deliver increasing levels of violence, both for status recognition and status mobility within the group. The orientation we discover under the current theme pervades the two previous themes. The social world is crafted towards a privileging of brute physicality over reason, which fuels the continuation of violence and narcissistic posturing. Conformity to the group in these tightly knit face-to-face communities is important to personal wellbeing; as Stuart explains, violence is a given from an early age:

'Ma mates fought so I'd just get involved... nobody really thought anything of it ... me dad used to fight when he was wee, he knows what it's like, so never bothered when I got into trouble from it... [I think] people from where I grew up as a wee guy just kind of thought cunts fight and that's that.'-(Stuart)

To help achieve status, groups would actively mark out a territory and seek out confrontations with groups from outside that territory. Although fights could occur spontaneously should accidental meetings occur, often they would be organized in advance; typically, through social networking, mobile phones, text messaging, pirate radios (though the latter was applicable to older generations). The police force coined the judgmental term 'recreational violence' to refer to these violent group practices. That analysis ignores the importance of respect, recognition, and achievement that commitment to inter-scheme conflict might provide: Celebrity status is rooted in violence. Even without notice, groups were aware that on certain nights, such as Fridays and Saturdays, it was likely rival gangs would actively seek violent confrontations by entering territorial boundaries or 'hanging out' at certain places. The danger of this point of reference for celebrity lies in the possibility of being a victim of serious injury. Boab and Jamesy explain:

'I don't leave the house without being tooled up (carrying a weapon), it's too dangerous man. Ye never know who you're going bump in to.'-(Boab)

'It could be kind of pure edgy [in scheme A]. [It is] a tad intimidating ... because you got the junkie flats along the Main street... [and the] old pub, I never liked walking to the garage at night, but my mum would always send me for fucking milk, or fucking bread (laughs). Pure knowing, I could get attacked as well, [but] still sending me for a fucking loaf man (laughs)... I always pocketed a blade wi' me [when I was sent] ... Nothing ever happened, [but] in case. I felt on the edge, know, cause you hear shit ... Fact, once a guy acted wide, but nuttin' came of it. Think he was just out [the pub], mad wi' it. I was ready for plugging the cunt.'-(Jamesy)

In anticipation of battle, arming himself with a variety of weaponry, Boab lives in fear of his life once outdoors. Jamesy suggests some heroism was involved in running his mother's food errands, but his voice foregrounds the perceptions of place. The environment contains sites where he might be ambushed. His choice of weapon carrying and aggression was less connected with a violent disposition, but rather with the need to protect himself in spaces he perceives pregnant with threat. The warrant for violence lay in self-protection. Pre-arming themselves is also recognized as a source of gaining status recognition among peers. Those producing the most imaginative or dangerous weaponry forms are often given 'street credit' by peers, becoming brief celebrities. This would encourage an escalation of this type of practice. However, even though weaponry was often simply for show, sometimes during fights these weapons would be used, even if reluctantly; often out of fear of being assaulted or for fear of stigmatization by peers as being a 'poof', 'gay', or a 'bitch' should the weapon not be used if the opportunity arose. This protest masculinity distances itself from passive femininity, with denigrating linguistics expressive of belonging to a hegemonic code producing hate speech directed at human difference. William rationalizes his knife attack by his need to avoid, at all costs, being identified as a "bitch": 
'When I fought...never really know them (the opponents) ... when I stabbed ... one o' their top boys a while back, I thought fuck sake man when the blade went in, but then I was pure like fuck it man, afterwards ... wid have been him or me.'-(Dean)

If you didn't do it (Use weapon) then you'd be considered a bitch.'-(William)

Showing a willingness to assault an opponent is perceived as a demonstration of bravery, it gives "top guy" status, as Billy describes below. Delivering violence is typically only perceived to be worthwhile if done so in front of an audience, to gain a celebrity status. However, should the opportunity arise to commit assault on a rival and then not be taken in front of an admiring audience, status could plummet:

'Was probably about 15 of us who always hung about with each other. Me and my 3 best pals then the rest of the team ... I was probably the top guy in the team ... so obviously I had all them (best friends who were also considered to be leaders or have a similar degree of social status) behind me fur support. Could do what I wanted.'-(Billy)

Collective rather than individualistic effort characterizes these boys' lives on the estates. Backing by the peer group legitimates offending practices, but it also encourages the narcissism of self-indulgence-Billy talks of doing what "I wanted." The verbalizing of strength and insult were initial drivers for settling group confrontations or imposing emotional sanctions (Rafanell 2013). Utterances contained expletives expressing bravado, or derogatory language was annexed to deny the manhood of opponents. In this case, the hate speech was homophobic and misogynist. The resulting shame from negative utterances, either segregates the individual who could accept the newly imposed role or (as in most cases) leads to an overwhelming rejection of the subaltern role. To regain lost or dwindling status and retrieve a vanishing manhood, violence was required. The target of this victimization had no choice but to "stand their ground". Ben explains:

'I don't think I could respect somebody that wouldn't stand their ground. aye, I would think they were a bitch for it ... they'd need to prove themselves before I'd hang about wi' them honestly.' -(Ben)

Being ostracized and bringing dishonor upon self and family, as Ti argues, arises from making the 'wrong' decision. It is exorcised by "stabbing fuck out the guy". Despite damaging mental health, the assault is perceived as being determined:

'Don't like saying it cause it still hurts but I did bitch it from this guy man ... ma pals lost a lot of respect for me, fuck, even my mam (Mother) was shamed, she seen it ... ended up stabbing fuck out the guy over pure fuck all years later man ... no proud of myself mate ... had to get that monkey off my back though.'-(Ti)

This cyclical process - a display of toxic masculinity and ensuing violence-is associated with the belief that without regularly affirming status through producing violence, not only would they become ostracized and possibly victimized, having been othered in homophobic terms. Violent acts, valorized by peers, undermine commitment and respect for conventional social norms by replacing them with delinquent ones. Once criminogenic drift occurs, a criminal record grows and criminal friendships flourish, whilst recognition and labelling as deviant cements that status, so reintegration into conventional worlds becomes extremely difficult. There are massive costs incurred by acceptance of a morally questionable celebrity status, recognized only after the events. Societal memory in the form of the criminal record keeps the offender ensconced within that troubled life history, where celebrity status is not only transitory, but destructive of their wellbeing in the longer-term.

\section{Conclusions}

The social life of the participants in this study is constructed around networks of interaction, so group dynamics are vital for understanding their behavior (Blumer 1969). Ellis et al. (1978) present 
group models of informational processes within internal and external environments, two of which are particularly relevant for this study. Firstly, displaying the defensive group model, Glasgow's marginalized youths receive information from constraining external forces, which results in reactive procedures. Overbearing tension in the form of adversity, marginalization, stigmatization, isolation, and the imposed values of higher classes (Willis 1977) can also cause groups to erect barriers and turn inwards (Ellis et al. 1978). This proceeds towards an adoption of the intensive group model, whereby youths recede from external influences and refocus informational processes inwards among peers. Validation of behavior no longer comes from outside, but rather from within this social-psychological dynamic (Rafanell 2013). As external exchanges become ever more limited for tension reduction, the goal ultimately becomes divorced from the external, in turn increasing investment in intrapersonal aspects of inter-member communication designed primarily to serve the self, which in this context must be constantly vigilant (Ellis et al. 1978).

The purpose of this study was to identify the formation of violence, and its association with supporting street capital of an aggressive nature. Street gangs exist in almost every housing estate within Glasgow, even among those perceived to be suffering relatively low deprivation, and they also exist in Paisley, Greenock, Edinburgh, and other Scottish cities (Bradshaw 2005). It follows that the considerable differences between Glasgow and the rest of Scotland relating to levels of violence cannot simply be attributed to structural factors, deprivation, or even street gang existence. Rather, culture within local areas, which articulates with notions of a wider masculinity and materialism provides the cohesive bond for variables whilst simultaneously adding an extra dimension to increasing levels of violence. Mainstream culture, for instance, the aggression apparent in many sports, offers unintended support to violent participation, effectively making it acceptable, accessible, and ultimately an attribute of a certain male identity, with the added lure of celebrity status. (Patrick 1973; Whitehead 2002). Coupled with social and structural constraints hindering marginalized members from fully integrating into mainstream society, young adolescent males have adopted those easily available aspects of mainstream culture connected with hegemonic values pertaining to manliness. This process leads to peer groups erecting barriers, turning inwards, and continually reinforcing a subcultural value system advocating the expression of hegemonic masculinity through a monopolized yet toxic or protest demeanor. Once set in train through the daily activities of estate life, these face-to-face micro-interactions perpetuate volatile peer practice.

A key feature of both the Community Initiative to Reduce Violence (Deuchar 2013), and the No More Knives, Better Lives initiative (Deuchar et al. 2014), was changing existing perspectives of a hegemonic masculinity mentality. ${ }^{2}$ Both projects aimed to make aware the negative consequences that violent behavior has on the victim and upon the victim's wider social networks of family, friends, and community. Results arguably suggest the approach has led to significant reductions of serious violence. However, both projects failed to incorporate notions of femininity or a non-violent kind of masculinity, containing pro-social values of citizenship; male identity remains associated with patriarchal notions, where power interconnects with aggression. Unless a wider patriarchal domination is also critically examined, protest masculinity may remain a prominent identity for working-class youths living in Glasgow's estates, whose conformity to an interpretation of hegemonic masculinity is palpable.

Although teenage street gangs were typically defined by invisible and porous territorial boundaries, somewhat recognizable by postcode references, they did not fight simply because of postcode differences. Rather, postcode differences became an available mechanism enabling masculine identity to be gained through violence. The group dynamics we describe in our themes strengthens a subcultural ideology. The intensified masculinity becomes toxic. Individuals who did not adhere to perpetuating a heterosexual masculine persona are othered and subjected to

2 www.cjscotland.co.uk/ 
emotional sanctioning, typically using femininized or homophobic utterances aimed to weaken them through de-masculinizing a self-image. Once sedimented into this social construction of merit, group ideology is particularly hard to break down, particularly without the availability and accessibility of other resources, such as leisure opportunities or meaningful employment, to sustain a non-violent masculinity.

Author Contributions: R.M. carried out field research, collected data, drafted original article. C.H. redrafted article, attended reviewers comments.

Funding: This research received no external funding

Conflicts of Interest: The authors declare no conflicts of interest

\section{References}

Adelson, Joseph. 1980. Handbook of Adolescent Psychology. New York: Wiley.

Austin, Roy L. 1980. Adolescents Subcultures of Violence. The Sociological Quarterly 21: 545-61. [CrossRef]

Bartie, Angela. 2010. Moral panics and Glasgow Gangs: Exploring 'The New Wave of Glasgow Hooliganism', 1965-1970. Contemporary British History 24: 385-408. [CrossRef]

Bauman, Zygmunt. 2004. Wasted Lives: Modernity and Its Outcasts. Cambridge: Polity.

Best, Shaun. 2016. Zygmunt Bauman: On what it means to be excluded. Power and Education 8: 124-39. [CrossRef] Blumer, Herbert. 1969. Symbolic Interactionism: Perspective and Method. Englewood Cliffs: Prentice Hall.

Boyle, Jimmy. 1984. The Pain of Confinement: Prison Diaries. Edinburgh: Canongate Press.

Bourdieu, Pierre. 1984. Distinction: A Social Critique of the Judgement of Taste. Cambridge: Harvard University Press.

Bradshaw, Paul. 2005. Terrors and Young Teams: Youth Gangs and Delinquency in Edinburgh. In European Street Gangs and Troublesome Youth Groups. Edited by Scott Decker and Frank Weerman. Walnut Creek: Altamira Press.

Carr, Rosalind. 2008. The Gentleman and the Soldier: Patriotic Masculinities in Eighteenth-Century Scotland. Journal of Scottish Historical Studies 28: 102-21. [CrossRef]

Cooley, Will. 2010. "Vanilla Thrillas": Modern Boxing and White-Ethnic Masculinity. Journal of Sport and Social Issues 34: 418-37. [CrossRef]

Connell, Robert William. 1995. Masculinities. Berkeley: University of California Press.

Connell, Robert William. 2005. Masculinities. Cambridge: Polity Press.

Davies, Andrew. 2013. City of Gangs: Glasgow and the Rise of the British Gangster. London: Hodder and Stoughton.

Coster, Stacy De, and Karen Heimer. 2001. The relationship between law violation and depression: An interactionist analysis. Criminology 39: 799-836. [CrossRef]

Devine, Thomas Martin. 1999. The Scottish Nation 1700-2000. London: Penguin.

Deuchar, Ross. 2009. Gangs, Marginalised Youth and Social Capital. Stoke-on-Trent: Trentham Books.

Deuchar, Ross. 2013. Policing Youth Violence: Transatlantic Connections. London: Trentham Books/IOE Press.

Deuchar, Ross, and Chris Holligan. 2010. Gangs, sectarianism and social capital: A qualitative study of young people in Scotland. Sociology 44: 13-30. [CrossRef]

Deuchar, Ross, Johanne Miller, and Mark Barrow. 2014. Breaking down barriers with the usual suspects: Findings from a research-informed intervention with police, young people, and residents in West of Scotland. Youth Justice. [CrossRef]

Ellis, Donald, G. Werbel, S. Wayne, and Fisher Aubrey. 1978. Towards a systematic organization of groups. Small Group Behaviour: An International Journal of Therapy, Counselling, and Training 9: 451-69.

Fraser, Alistair David. 2015. Urban Legends: Gang Identity in the Post-Industrial City. Oxford: Oxford University Press. Flick, Uwe. 2014. An Introduction to Qualitative Research. London: Sage.

Furedi, Frank. 2010. Celebrity Culture. Society 47: 493-97. [CrossRef]

Gray, Andrew. M. 1989. A History of Scotland: Modern Times. Oxford: Oxford University Press.

Holligan, Chris, and Ross Deuchar. 2014. What does it mean to be a man? Psychosocial undercurrents in the voices of incarcerated (violent) Scottish teenage offenders. Criminology and Criminal Justice 15: 361-77. [CrossRef]

Innes, Martin, and Nigel Fielding. 2002. From Community to Communicative Policing: "Signal Crimes" and the Problem of Public Reassurance. Sociological Research Online 7: 1-12. [CrossRef]

Jeffrey, Robert. 2002. Gangland Glasgow: True Crime from the Streets. Edinburgh: Black and White. 
Johnston, Ronnie, and Arthur McIvor. 2004. Dangerous Work, Hard Men and Broken Bodies: Masculinity in the Clydeside Heavy Industries. 1930-1970s. Labor History Review 69: 135-51. [CrossRef]

King, Peter. 2011. Urbanisation, rising homicide rates and the geography of lethal violence in Scotland 1800-1860. Journal of the Historical Association 96: 231-59.

Klein, Malcolm W. 1971. Street Gangs and Street Workers. Englewood Cliffs: Prentice Hall.

Kupers, Terry A. 2005. Toxic masculinity as a barrier to mental health treatment in prison. Journal of Clinical Psychology 61: 713-24. [CrossRef] [PubMed]

Lacuone, David. 2005. "Real Men are Tough Guys": hegemonic masculinity and safety in the construction industry. The Journal of Men's Studies 13: 247.

Link, Bruce G., and Jo Phelan. 1995. Social conditions as fundamental causes of disease. Journal of Health and Social Behavior 35: 80-94. [CrossRef]

Matza, David. 1964. Delinquency and Drift. New York: Wiley.

Matza, David, and Gresham M. Sykes. 1961. Juvenile Delinquency and Subterranean Values. American Sociological Review 26: 712-19. [CrossRef]

Falco Metcalfe, Christi, and Thomas Baker. 2014. The Drift from Convention to Crime: Exploring the Relationship Between Co-Offending and Intermittency. Criminal Justice and Behavior 41: 75-90. [CrossRef]

Messerschmidt, James W. 1993. Masculinities and Crime: Critique and Reconceptualization of Theory. Totowa: Rowan and Littlefield.

Mullen, Kenneth, Jonathan Watson, Jan Swift, and David Black. 2007. Young men, masculinity and alcohol. Drugs: Education, Prevention, and Policy 14: 151-65. [CrossRef]

Mullins, Christopher. W. 2006. Holding Your Square: Masculinities, Street Life and Violence. Portland: Willian.

Ness, Kate. 2012. Constructing Masculinity in the Building Trades. Gender, Work and Organization 19: 654. [CrossRef] Patrick, James. 1973. A Glasgow Gang Observed. Wiltshire: Redwood Press.

Quin, Daniel, Jessica A. Heerde, and John W. Toumbourou. 2018. Teacher support within an ecological model of adolescent development: Predictors of school engagement. Journal of School Psychology 69: 1-15. [CrossRef]

Rafanell, Irene. 2013. Micro-situational Foundations of Social Structure: An Interactionist Exploration of Affective Sanctioning. Journal for the Theory of Social Behaviour 43: 181-204. [CrossRef]

Rodger, John. J. 2008. Criminalising Social Policy. Devon: Willian Publishing.

Silverman, D. 2011. Qualitative Research. London: Sage.

Smith, David John. 2006. Social Inclusion and Early Desistance from Crime. University of Edinburgh, Centre for Law and Society. Available online: http://law.ed.ac.uk/cls/esytc/findings/digest12.pdf (accessed on 1 May 2017).

Stearns, Peter. N. 2010. Oxford Encyclopedia of the Modern World. Oxford: Oxford University Press.

Sutherland, Edwin. H. 1947. Principles of Criminology. Philadelphia: JB Lippincott.

Thrasher, Frederic Milton. 1927. The Gang: A Study of 1313 Gangs in Chicago. Chicago: University of Chicago Press. Wacquant, Loïc. 2004. Body and Soul: Notebooks of an Apprentice Boxer. Oxford: Oxford University Press. Walker, Gregory Wayne. 2006. Disciplining Protest Masculinity. Men and Masculinities 9: 5-22. [CrossRef] Whitehead, Stephen M. 2002. Men and Masculinities: Key Themes and New Directions. Cambridge: Polity Press.

Willis, Paul. 1977. Learning to Labor: How Working Class Kids Get Working Class Jobs. New York: Columbia University Press.

Woodward, Kath. 2014. Globalizing Boxing. London: Bloomsbury.

(C) 2018 by the authors. Licensee MDPI, Basel, Switzerland. This article is an open access article distributed under the terms and conditions of the Creative Commons Attribution (CC BY) license (http:/ / creativecommons.org/licenses/by/4.0/). 